\title{
Partisipasi Masyarakat dalam Pembangunan Dusun yang Inklusif
}

\author{
Arni Surwanti' ${ }^{1}$, Edi Supriyono ${ }^{2}$ \\ Magister Manajemen, Program Pascasarjana, Universitas Muhammadiyah Yogyakarta, J. Brawijaya Tamantirto Yogyakarta \\ Email:arni_surwanti@umy.ac.id \\ DOI: $10.18196 / p p m .32 .223$
}

\begin{abstract}
Abstrak
Dusun Polosiyo berada di Desa Poncosari, terletak di Kecamatan Srandakan, Kabupaten Bantul, Daerah Istimewa Yogyakarta. Pembangunan di Dusun Polosiyo diharapkan mengacu pada konsep Tujuan Pembangunan Berkelanjutan (Sustainable Development Goals/SDG's), yakni pembangunan dilaksanakan secara inklusif, termasuk bagi penyandang disabilitas. Permasalahan sosial ekonomi yang dihadapi dusun ini adalah belum ada profil dusun, usaha mikro warga Dusun Polosiyo yang memproduksi berbagai jenis keripik kualitas belum baik, belum memiliki kemasan yang baik. belum bisa dipasarkan dengan baik, masyarakat juga belum mampu untuk memanfaatkan berbagai jaringan yang ada di desa untuk memasarkan produknya. Taman Pendidikan Alquran di Dusun Polosiyo juga belum berjalan baik karena tidak adanya warga yang menjadi penggerak kegiatan ini. Program KKN-PPM memberikan model untuk mengatasi berbagai permasalahan dengan melakukan penyusunan profil dusun dan kegiatan penyadaran (awairness raising) untuk meningkatkan perhatian pada penyandang disabilitas. Pemberdayaan ekonomi masyarakat Dusun Polosiyosecara inklusif dilakukan dengan meningkatkan pelatihan, peningkatan kualitas produk, dan pengemasan; meningkatkan jaringan pemasaran produk melalui BUMDesa Mukti Lestari Desa Poncosari; melaksanakan program bantu dengan mempersiapkan kader untuk pengelolaan Taman Pendidikan Alquran. Program KKN PPM ini menumbuhkan kesadaran masyarakat dan pemerintah dusun untuk memerhatikan penyandang disabilitas dan wirausaha mikro yang berpotensi untuk dikembangkan.
\end{abstract}

Kata Kunci: Inklusif, Peningkatan Kualitas, Pengemasan, Jaringan Pemasaran.

\section{Pendahuluan}

Dusun Polosiyo adalah salah satu pedukuhan yang berada di Desa Poncosari, Kecamatan Srandakan, Kabupaten Bantul, Daerah Istimewa Yogyakarta. Desa Poncosari kini dikenal dengan wisata pantainya yang akhir-akhir ini banyak menjadi favorit bagi wisatawan, terutama wisatawan lokal. Beberapa pantai yang sering dikunjungi di Desa Poncosari adalah Pantai Baru, Pantai Kuwaru, dan Pantai Pandansimo. Pada saat ini, Dusun Polosiyo memiliki 2 RT dengan penduduk 639 jiwa dari 235 kepala keluarga dan memiliki 2 organisasi kemasyarakatan, yaitu PKK dan Karang Taruna [1]. PKK berperan meningkatkan pengelolaan gerakan PKK, baik kegiatan perorganisasian maupun pelaksanaan program-programnya yang disesuaikan dengan situasi kondisi masyarakat setempat. Sementara Karang Taruna di Dusun Polosiyo berperan dalam penyelenggara usaha kesejahteraan social; penyelenggara pendidikan dan pelatihan bagi masyarakat; penyelenggara pemberdayaan masyarakat, terutama generasi muda di lingkungannya secara komprehensif, terpadu, dan terarah serta berkesinambungan; penyelenggara kegiatan pengembangan jiwa kewirausahaan bagi generasi muda di lingkungannya; penanaman pengertian, memupuk, dan meningkatkan kesadaran tanggung jawab sosial generasi muda; penumbuhan dan pengembangan semangat kebersamaan, jiwa kekeluargaan, kesetiakawanan sosial dan memperkuat nilai-nilai kearifan dalam bingkai Negara Kesatuan Republik Indonesia.

Program ini juga mengacu pada Peraturan Gubernur Daerah Istimewa Yogyakarta No. 34 Tahun 2018 [7] tentang Tujuan Pembangunan Berkelanjutan (TPB atau Sustainable Development Goals/SDG's) yang merupakan agenda pembangunan dunia yang diterbitkan pada tahun 2015 untuk mencapai kesejahteraan seluruh umat manusia di tingkat provinsi. Dokumen yang akan dilaksanakan sampai dengan tahun 2030 ini merupakan kesepakatan internasional 
yang disetujui oleh semua anggota PBB sehingga menjadi dokumen yang komprehensif dan inklusif. Tidak ada satu pun warga yang boleh ditinggalkan dalam sasaran pembangunan, termasuk di dalamnya penyandang disabilitas. Tujuan Pembangunan yang diangkat dalam program KKN PPM ini adalah peniadaan kemiskinan, pekerjaan layak, dan pertumbuhan ekonomi. Oleh karena itu, pemberdayaan ekonomi akan dilakukan secara inklusif antara masyarakat dan melibatkan penyandang disabilitas.

Masyarakat di Dusun Polosiyo saat ini banyak yang melakukan wirausaha. Beberapa produk makanan yang berupa beberapa jenis keripik telah dihasilkan oleh masyarakat Dusun Polosiyo. Namun, saat ini produk tersebut belum bisa dipasarkan dengan baik. Hal ini disebabkan produk masih kurang baik kualitasnya dan belum memiliki kemasan yang baik. Masyarakat juga belum mampu memanfaatkan berbagai jaringan yang ada di desa untuk memasarkan produknya. Sementara itu, sebagaimana di wilayah lain, di Dusun Polosiyo terdapat penyandang disabilitas yang belum mendapatkan perhatian dari masyarakat. Hal ini dibuktikan dengan belum adanya data terkait penyandang disabilitas di desa dan di tingkat dusun. Ketidaktersediaan data yang valid dan tidak memliki kartu identitas diri menyebabkan penyandang disabilitas tidak bisa mendapatkan layanan-layanan yang ada dalam program pemerintah. Program-program tersebut antara lain jaminan kesehatan, program pendidikan, program pelatihan, dan program-program pemberdayaan ekonomi yang tidak bisa diakses oleh penyandang disabilitas. Taman Pendidikan Alquran di Dusun Polosiyo juga belum berjalan secara rutin karena tidak ada warga yang menjadi penggerak kegiatan ini.

Program KKN-PPM memberikan model untuk mengatasi berbagai permasalahan dengan melakukan penyusunan profil dusun dan kegiatan penyadaran (awairness raising) untuk meningkatkan perhatian pada penyandang disabilitas. Pemberdayaan ekonomi masyarakat Dusun Polosiyo secara inklusif dilakukan dengan meningkatkan pelatihan peningkatan kualitas produk dan pengemasan; meningkatkan jaringan pemasaran produk melalui BUM Desa Mukti Lestari Desa Poncosari; melaksanakan program bantu dengan mempersiapkan kader untuk pengelolaan Taman Pendidikan Alquran. Program KKN PPM ini menumbuhkan kesadaran masyarakat dan pemerintah dusun untuk memperhatikan penyandang disabilitas dan wirausaha mikro yang potensi untuk dikembangkan

\section{Metode Pelaksanaan}

KKN PPM dilakukan dengan partisipasi masyarakat dusun secara inklusi dalam pembangunan di tingkat dusun. Program dan kegiatan yang direncanakan dan dilaksanakan berdasar evaluasi potensi dusun dengan mempertimbangkan masyarakat penyandang disabilitas. Program KKN PPM ini berupaya meningkatkan kesejahteraan ekonomi masyarakat secara inklusif. Program inklusif dilakukan dengan melibatkan penyandang disabilitas dan dengan melakukan awainess raising pada pemerintah desa yang ada di Dusun Polosiyo beserta organisasi kemasyarakatan yang ada di dusun, yaitu PKK dan Karang Taruna,

Sementara itu, pemerintah desa di Dusun Polosiyo beserta organisasi kemasyarakatan yang berada di bawah naungan pemerintah Desa Poncosari, yaitu PKK dan Karang Taruna, berpotensi menjadi pihak-pihak yang memfasilitasi penyandang disabilitas untuk mendapatkan haknya. Mereka perlu diperkenalkan tentang isue-isue disabilitas. Hal ini sesuai dengan fungsi pemerintah desa dan organisasi kemasyarakatan PKK dan Karang Taruna. Peran pemerintah desa, termasuk yang ada di dusun, berperan meningkatkan kualitas sumber daya manusia dan 
pelayanan terhadap masyarakat di berbagai bidang. Peran PKK adalah meningkatkan mental, spiritual, dan perilaku hidup dengan menghayati dan mengamalkan pancasila serta meningkatkan pelaksanaan hak dan kewajiban sesuai dengan hak azasi manusia, demokrasi, meningkatkan kesetiakawanan sosial dan kegotong-royongan serta membentukan watak bangsa yang selaras, serasi, dan seimbang.

\section{Mekanisme Pelaksanaan Kegiatan PPM}

Mekanisme pelaksanaan kegiatan PPM disusun melalui tahapan/perencanaan :

1. Persiapan dan pembekalan mahasiswa KKN-PPM yang perlu diberikan kepada mahasiswa.

Kegiatan ini akan dilaksanakan selama 7 hari, terdiri atas 4 hari pembekalan klasikal yang diselenggarakan oleh LP3M UMY, 2 hari untuk observasi ke lokasi guna mendapatkan gambaran potensi dan permasalahan yang ada di Dusun Polosiyo, Desa Poncosari, Srandakan, Bantul Yogyakarta, dan 1 hari untuk penyusunan program dan kegiatan. Pembekalan dilakukan dengan materi pemberdayaan, teknik dan strateginya. Pada pembekalan ini diberikan materi tentang cara melakukan asesment kebutuhan pada lokasi KKN sebagai dasar untuk perencanaan program dan kegiatan. Mahasiswa juga dibekali tentang materi isue disabilitas dan cara melakukan pendataan oleh DPL.

\section{Pelaksanaan Program KKN PPM}

Program pemberdayaan ekonomi masyarakat Dusun Polosiyo secara inklusi berdasarkan potensi dusun dan desa terdiri atas 4 besaran program, yaitu: pertama, penyusunan profil dusun, termasuk pendataan penyandang disabilitas yang ada di Dusun Polosiyo untuk mengetahui jumlah dan karakteristiknya. Kedua, peningkatan kesadaran (awairness raising) pemerintah desa dan masyarakat yang berada di dusun melalui organisasi kemasyarakatan yang ada di dusun agar meningkatkan perhatian pada kesejahteraan penyandang disabilitas. Ketiga, pemberdayaan ekonomi masyarakat Dusun Polosiyo dengan meningkatkan kualitas produk dan pengemasan, khususnya masyarakat Dusun Polosiyo yang saat ini melakukan wirausaha memproduksi produk makanan beberapa jenis keripik. Dalam program ini, dilakukan pelatihan keterampilan peningkatan kualitas dan ragam produksi keripik terhadap masyarakat Dusun Polosiyo oleh wirausahawan yang ada. Pelatihan ini dilakukan secara inklusif dengan melibatkan penyandang disabilitas. Pemberdayaan ekonomi juga dilakukan dengan meningkatkan kualitas pengemasan agar produk layak jual. Keempat, peningkatan jejaring pemasaran produk dengan memanfaatkan BUM Desa Mukti Lestari Desa Poncosari untuk menambah jumlah wirausaha di Dusun Polosiyo. Kelima, pelaksanaan program bantu berupa penyiapan kader Taman Pendidikan Alquran/TPA dan pengelolaan masjid. Gambaran pelaksanaan KKN PPM dapat dilihat pada skema pada halaman berikut:

\section{Hasil dan Pembahasan}

Penyusunan Profil Dusun

Penyusunan profil dusun memasukkan pendataan penyandang disabilitas yang ada di Dusun Polosiyo. Penyusunan profil desa dilakukan untuk melengkapi data administrasi dusun, baik dari segi jumlah kepala keluarga, balita, lansia, maupun kaum penyandang disabilitas. Melengkapi 
data administrasi ini bertujuan agar ada ketersediaan data jika sewaktu-waktu dibutuhkan. Program kerja pokok ini bekerja sama dengan Kepala Dusun Polosiyo.

Hasil kegiatan program utama dan program bantu dapat dilihat pada gambar 1.

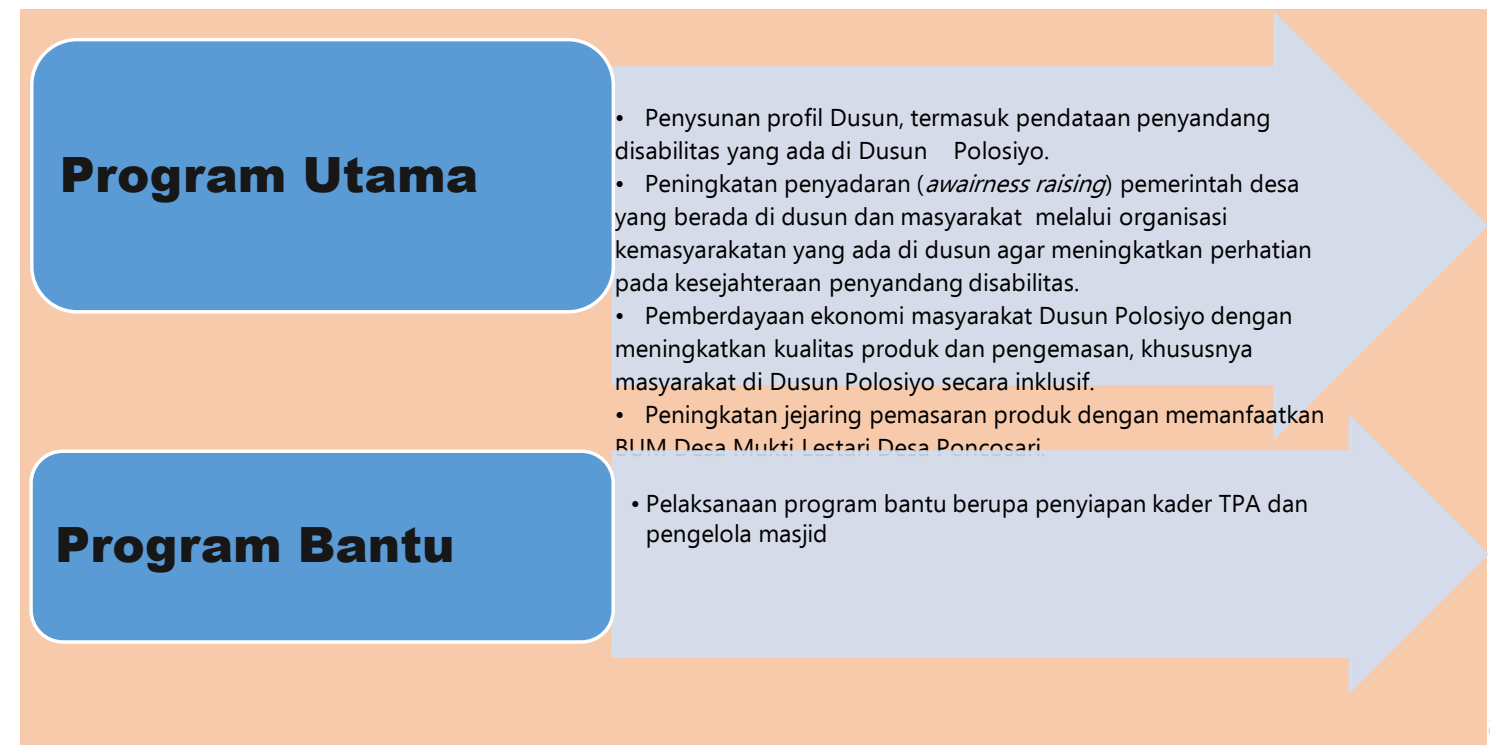

\section{Gambar 1. Konsep Kegiatan ini}

Kegiatan ini memberikan pengetahuan pentingnya ketersediaan data administrasi agar selalu siap sedia jika dibutuhkan sewaktu-waktu. Hasil dari kegiatan ini adalah Dusun Polosiyo memiliki data yang lengkap, baik itu warga yang masuk maupun yang pergi dari dusun. Sasaran kegiatan ini adalah masyarakat Dusun Polosiyo. Dari profil dusun ini juga bisa diidentifikasi beberapa objek wisata dan potensi usaha dusun yang dikembangkan untuk mendukung bagian wisata Desa Poncosari. Salah satu objek wisata tersebur adalah wisata makam religi Kiai Gebang dan wisata kuliner.
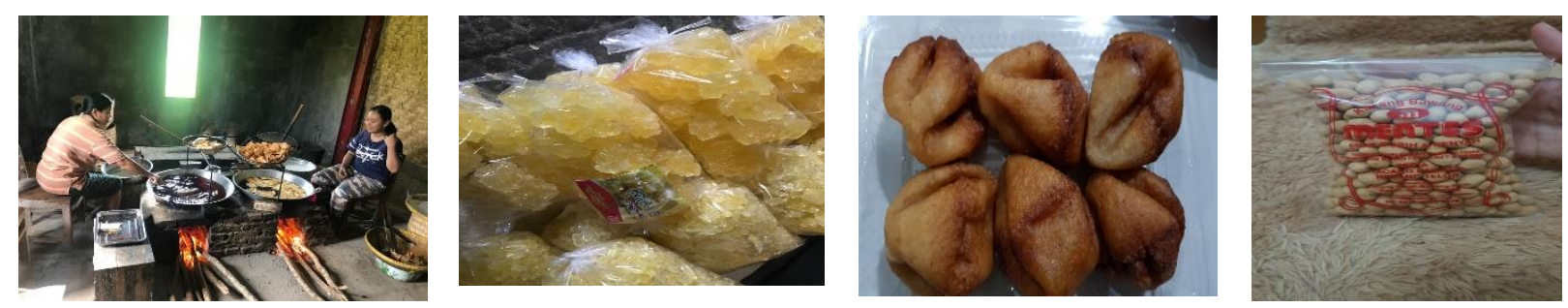

\section{Gambar 2. Wisata Kuliner Usaha Kripik Tempe, Wisata Kuliner, Gula Batu, dan Kacang Telur}

\section{Wisata Religi Makam Kiai Gebang Sari dan Wisata Kuliner}

Di Dusun Polosiyo, Kyai Gebang Sari adalah seseorang panglima perang dari Kerajaan Majapahit yang pernah singgah di Desa Polosiyo dan beliau yang menamakan dusun ini menjadi Desa Polosiyo. Konon beliau memiliki pusaka tombak yang di namai Kiai Guntur Geni. Pusaka ini menjadi nama dusun di Selatan Desa Polosiyo. Berdasarkan cerita dari masyarakat setempat, setiap satu tahun sekali, pusaka tersebut terlihat dinlangit membentuk tombak berwana merah seperti api. Hal ini terjadi saat masyarakat mengadakan pengajian tahunan di Dusun Polosiyo dan Gutur Geni. Dusun Polosiyo juga memiliki warga yang menjalankan beberapa usaha mikro yang bergerak di bidang kuliner, seperti pembuatan keripik tempe, gula batu, adrem, dan kacang 
telur. Berbagai tempat usaha ini juga dijadikan objek wisata yang ditawarkan Desa Poncosari, khususnya wisata sepeda. Para pesepeda ini akan diampirkan ke beberapa usaha mikro yang berada di Desa Poncosari, termasuk Dusun Polosiyo. Wisatawan ini selain bisa melihat usaha mikro ini, juga diharapkan bisa menjadi konsumen dari usaha-usaha mikro tersebut.

Peningkatan penyadaran (awairness raising) pada kesejahteraan penyandang disabilitas.

Peningkatan penyadaran (awairness raising) pemerintah desa dan masyarakat yang berada di dusun dilakukan melalui organisasi kemasyarakatan yang ada di Dusun Polosiyo. Sosialisasi terkait dengan materi disabilitas ini memiliki tema "Rekomendasi untuk Memajukan Hak-Hak Asasi Penyandang Disabilitas”. Kegiatan ini mengacu pada UU No. 19 tahun 2011 [2] tentang pengesahan konvensi hak penyandang disabilitas, UU No.8 tahun 2016 tentang Penyandang Disabilitas, [3] PERDA Provinsi No. 4 tahun 2012 Daerah Istimewa Yogyakarta terntang Perlindungan dan Pemenuhan Hak Penyandang Disabilitas [4] serta PERDA Kabupaten Bantul No. 11 tahun 2015 tentang Pemenuhan Hak-Hak Penyandang Disabilitas [5]. Kegiatan sosialisasi ini diharapkan mampu meningkatkan kepedulian terhadap kaum penyandang disabilitas di lingkungan masyarakat. Maksud dari kegiatan ini adalah memberi pengetahuan kepada masyarakat Dusun Polosiyo terkait disabilitas dan hak-haknya, seperti pendidikan, kesehatan, ketenagakerjaan, dan sebagainya. Sasaran kegiatan ini adalah masyarakat Dusun Polosiyo, terutama elemen perangkat dusun dan tokoh masyarakat.
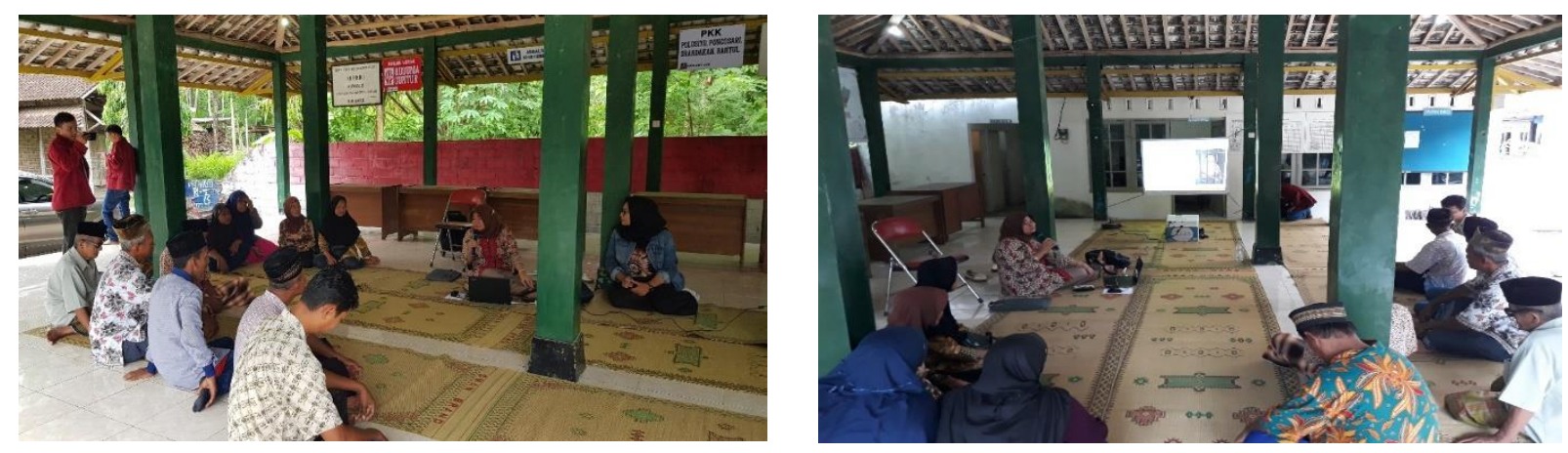

Gambar 3 Peningkatan Penyadaran (awairness raising) pada Kesejahteraan Penyandang Disabilitas

Pemberdayaan ekonomi masyarakat Dusun Polosiyo dengan meningkatkan kualitas produk dan pengemasan, khususnya masyarakat di Dusun Polosiyo secara inklusif.
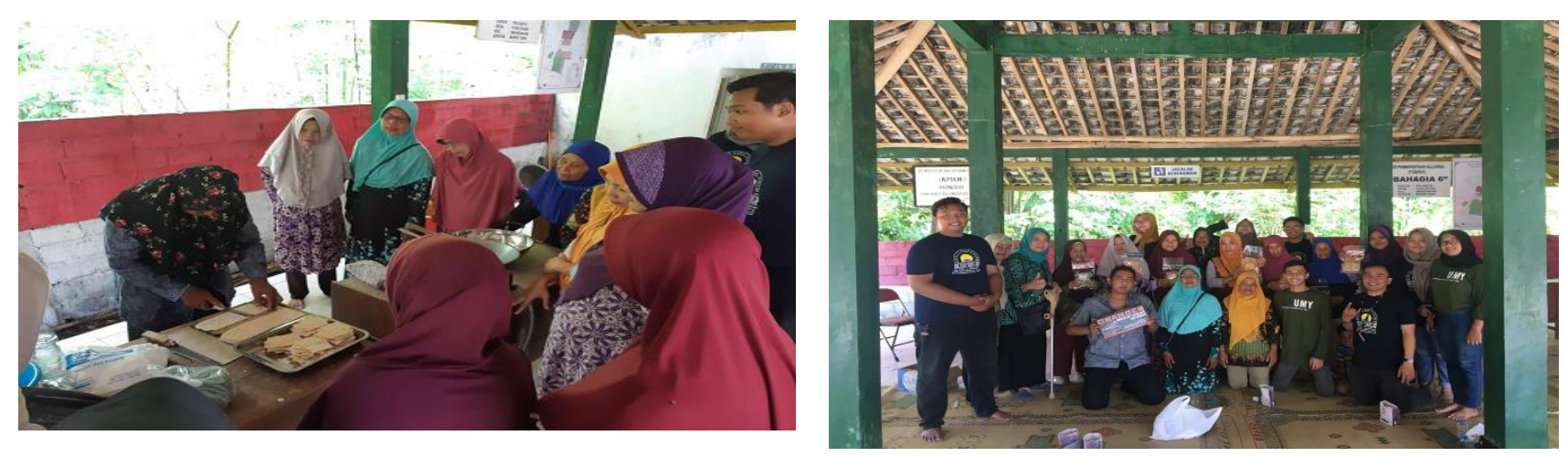

Gambar 4. Pelatihan Ketrampilan Pembuatan Makanan Kering Dan Pengemasannya 
Adanya UMKM di Dusun Polosiyo sebetulnya memiliki potensi, tetapi perlu adanya perbaikan kemasan supaya lebih menarik. Perbaikan kemasan dan keterampilan yang diadakan oleh peserta KKN mendapat antusias yang cukup luar biasa dari ibu-ibu di Dusun Polosiyo. Kegiatan ini memberi pengetahuan kepada masyarakat, kususnya ibu-ibu yang memiliki usaha UMKM atau yang ingin memiliki dan mengembangkan bakatnya di bidang pembuatan makanan kering, seperti keripik dari berbagai bahan.

Program pelatihan keterampilan dilakukan untuk membangun kreatviitas masyarakat yakni dengan membuat berbagai macam kripik dan membaiki kemasan. Kegiatan dilaksanakan secara inklusi. Artinya, penyandang disabilitas juga menjadi bagian di dalamnya. Program perluasan kesempatan kerja bagi penyandang disabilitas ini memberikan kesempatan kerja bagi penyandang disabilitas [6]. Program kerja ini menghasilkan beberapa manfaat, seperti pelatihan membuat label kemasan. Dalam program ini, juga turut disampaikan bahwa hal apa saja yang perlu ada di dalam label kemasan.

Peningkatan jejaring pemasaran produk dengan memanfaatkan BUM \Desa Mukti Lestari Desa Poncosari.

Pelaksanaan pengabdian, terutama dalam pelaksanaan pemasaran UMKM di Dusun Polosiyo, yang direncanakan bisa dipasarkan melalui BUMDesa Mukti Lestari karena BUMDesa ini sudah memiliki wadahnya, tetapi belum berjalan dengan baik. Pada kegiatan KKN PPM ini, sudah ada komitmen dari pemerintah desa untuk menghidupkan BUM DEsa Mukti Lestari sebagai salah satu media penjualan produk UMKM yang ada di Dusun Polosiyo selain produknya dipasarkan melalui berbagai toko dan pasar.
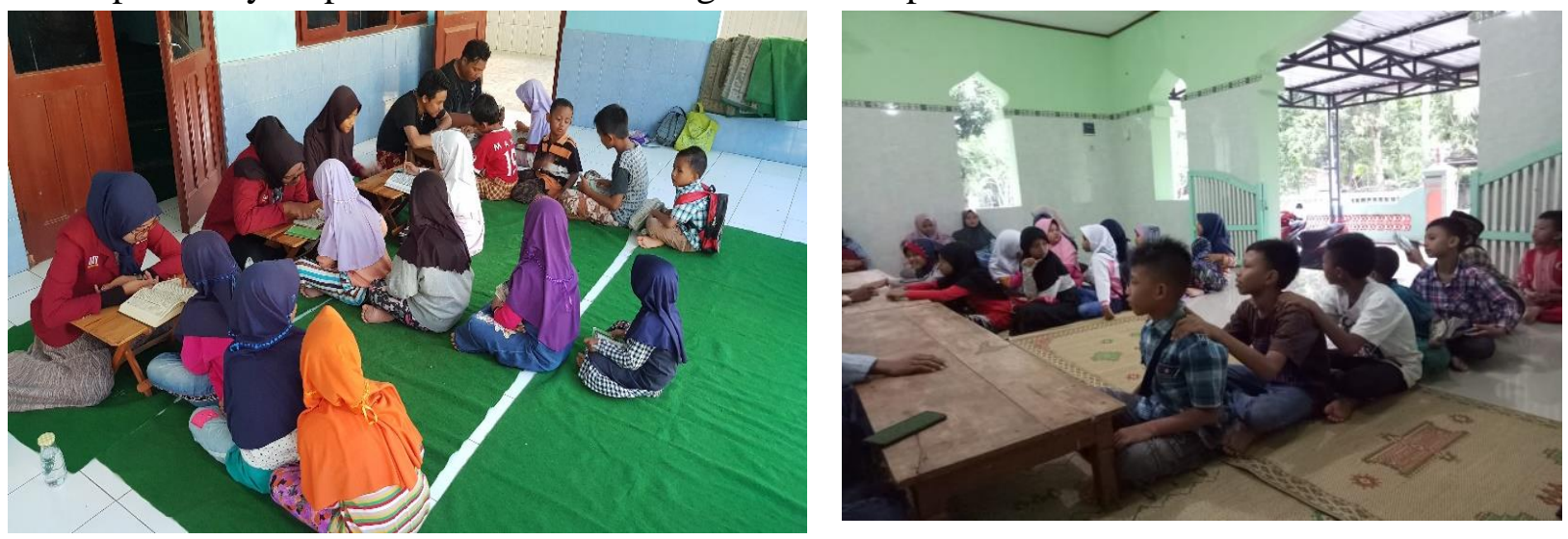

Gambar 5 Pelaksanaan Program Bantu Berupa Penyiapan Kader TPA dan Pengelola Masjid Pelaksanaan Program Bantu: Penyiapan Kader TPA Dan Pengelola Masjid

Program bantu yang dilaksanakan KKN PPM ini adalah pelaksanaan program bantu berupa penyiapan kader TPA dan pengelola masjid. Taman Pendidikan Alquran yang ada di Dusun Polosiyo ini memiliki tempat pembelajaran di dua masjid, yaitu masjid An-Nur dan masjid AlFurqon. Biasanya, masjid Al-Furqon ini adalah tempat pembelajaran Alquran untuk warga RT 01 hingga 03, sedangkan di masjid An-Nur adalah tempat pembelajaran Alquran untuk warga RT 04 hingga 06. Pembelajaran Alquran di masjid An-Nur diadakan pada hari Senin dan Kamis, sedangkan untuk masjid Al-Furqon diadakan pada hari Rabu dan Sabtu. Pada awal KKN, kegiatan pembelajaran Alqur'an dilaksanakan secara tidak aktif. Tim KKN mengaktifkan kembali melalui memberikan bantuan penyediaan tenaga pengajar melalui Badko, yaitu Badan Koordinasi Taman Pendidikan Quran dari pesantren Ar-Rahman. Pada kegiatan KKN PPM 
disiapkan tenaga pengajar dari karang taruna dusun. Tenaga pengajar dari karangtaruna dusun disiapkan untuk menjadi tenaga pengajar dan diberikan pengetahuan cara mengelola masjid. Para tenaga pengajar melalui Badko ini ikut mengajari anak-anak di Dusun Polosiyo. Para santri dari pesantren Ar-Rahman juga melatih tenaga pengajar TPA yang berasal dari karang taruna dusun. Pada waktu yang akan dating, para pemuda dari karang taruna ini bersedia mengajar TPA dan mengelola masjid dengan lebih baik lagi.

\section{Simpulan}

Program KKN-PPM memberikan model untuk mengatasi berbagai permasalahan dengan melakukan penyusunan profil dusun dan kegiatan penyadaran (awairness raising) untuk meningkatkan perhatian pada penyandang disabilitas. Pemberdayaan ekonomi masyarakat Dusun Polosiyo dilakukan secara inklusif untuk meningkatkan pelatihan peningkatan kualitas produk dan pengemasan; meningkatkan jaringan pemasaran produk melalui BUMDesa Mukti Lestari Desa Poncosari; melaksanakan program bantu dengan mempersiapkan kader untuk pengelolaan Taman Pendidikan Alquran dan meningkatkan pemahaman pengelolaan masjid yang lebih baik.

\section{Ucapan Terima Kasih}

Kegiatan KKN PPM ini didukung oleh Universitas Muhammadiyah Yogyakarta dalam bentuk dukungan materiil dan nonmateriil. Kami mengucapkan terima kasih kepada pemberi dana, yaitu Universitas Muhammadiyah Yogyakarta berdasarkan nomor kontrak 031/PENLP3M/I/2020 dan telah memfasilitasi pelaksanaan KKN-PPM. Ucapan terima kasih juga kami sampaikan kepada Bapak Sumardi, selaku Kepala Dusun Desa Polosiyo yang telah menyediakan informasi dan tempat untuk pelaksanaan KKN-PPM.

\section{Daftar Pustaka}

https://kecSrandakan.bantulkab.go.id/desa/poncosari (diunduh 24 Desember 2019).

Republik Indonesia. 2011. Undang-Undang Nomor 19 tahun 2011 tentang Pengesahan Convention on the Rights of Persons with Disabilities (Konvensi mengenai Hak-Hak Penyandang Disabilitas). Lembaran Negara Republik Indonesia Tahun 2011 Nomor 107. Sekretariat Negara. Jakarta.

Republik Indonesia. 2016. Undang-Undang Nomor 8 tahun 2016 tentang Penyandang Disabilitas. Lembaran Negara Republik Indonesia Tahun 2016 Nomor 107. Sekretariat Negara. Jakarta.

Republik Indonesia. 2012. Peraturan Daerah Provinsi Daerah istimewa Yogyakarta Nomor 4 Tahun 2012 tentang Perlindungan dan Pemenuhan Hak-Hak Penyandang Disabilitas. Lembaran Daerah Provinsi Daerah Istimewa Yogyakarta Tahun 2012 Nomor 4. Sekretariat Daerah Provinsi Daerah Istimewa Yogyakarta. Yogyakarta

Republik Indonesia. 2015. Peraturan Daerah Provinsi Kebupaten Bantul Nomor 11 Tahun 2015 tentang Pemenuhan Hak-Hak Penyandang Disabilitas. Lembaran Daerah Kabupaten Bantul Tahun 2015 Nomor 53. Sekretariat Daerah Kabupaten Bantul Yogyakarta

Surwanti.,Arni., 2017. Analisis Pemberdayaan Ekonomi Penyandang Disabilitas Melalui Wirausaha Mandiri Berdasarkan Perda Propinsi DIY No 4 Tahun 2012 Tentang Perlindungan Dan Pemenuhan Hak-Hak Penyandang Disabilitas., Working Paper.

Peraturan Gubernur Daerah Istimewa Yogyakarta No. 34 Tahun 2018 Tentang Rencana Aksi Daerah Tujuan Pembangunan Berkelanjutan Tahun 2018-2022. 